\title{
Políticas públicas para o urbano em Guarapuava, PR, Brasil
}

\section{Políticas públicas para el urbano en Guarapuava, PR, Brasil}

\section{Public policies for the urban in Guarapuava, PR, Brazil}

\author{
Tatiellen Cristina Prudentes \\ tatiellencristina@hotmail.com \\ Universidade Estadual do Centro-Oeste, UNICENTRO, Guarapuava, PR \\ Marcia da Silva \\ marcia.silvams@gmail.com \\ Universidade Estadual do Centro-Oeste, UNICENTRO, Guarapuava, PR
}

\begin{abstract}
Resumo: Analisa-se as formas de intervenção urbana a partir de políticas públicas, com recursos oriundos do governo federal, numa cidade média do estado do Paraná, entre 2013 e 2016. Os resultados são apresentados em três seções. Na primeira, apresentase a revisão de conceitos e temáticas voltadas para as políticas públicas; na segunda etapa, apresenta-se e discute-se dados documentais, de instituições governamentais e não governamentais, e entrevistas. Na terceira etapa, descreve-se os convênios estabelecidos entre o governo federal e o governo local, em termos de políticas públicas de intervenção para o espaço urbano. Conclui-se que, em Guarapuava, os fatores políticos muito intervêm na distribuição de políticas públicas com o intuito de promoção, enaltecimento e perpetuação de determinados grupos de e no poder, em especial os grupos familiares e seus alinhamentos políticos e partidários.
\end{abstract}

Palavras-chave: Estado; Ações Públicas; Convênio; Conflitos de Interesses.

Resumen: Buscase analizar las formas de intervención urbana de políticas púbicas con recursos provenientes del gobierno federal, en una ciudad media en el estado de Paraná, entre 2013 y 2016. Los resultados san-presentados en tres secciones. En la primera presentase la revisión de conceptos y temas centrados en las políticas públicas; en la segunda etapa, se presenta y se discute datos documentales de instituciones gubernamentales y no gubernamentales y entrevistas. En la tercera etapa, se describen los acuerdos establecidos entre el gobierno federal y el gobierno local, en términos de políticas de intervención pública para el espacio urbano. Concluye que en Guarapuava los factores políticos intervienen en la distribución de políticas públicas con el propósito de provisiónenlo, enaltecimiento y perpetuación de un grupo de poder. Intenciones y discursos son dirigidas por intereses y conflictos, conducidas por grupos de poder familiar, que privilegian sus alineamientos políticos y partidarios.

Palabras clave: Estado; Acciones Públicas; Convenio; Conflictos de Intereses.

Abstract: We analyze the forms of urban intervention based on public policies, with resources from the federal government, in a medium-sized city in the state of Paraná, between 2013 and 2016. The results are presented in three sections. In the first, we review concepts and themes focused on public policies; In the second one, we present and discuss documentary data, from governmental and non-governmental institutions, and interviews. In the third one, we describe the covenants established between the federal government and the local government, in terms of public policies 
to an intervention of the urban space. It is concluded that, in Guarapuava, the political factors are very intervening in the distribution of public policies in order to promote, enhancement and perpetuate certain groups of and in power, especially family groups and their political and party alignments.

Keywords: State; public actions; Covenant; Conflicts of Interest.

\section{INTRODUÇÂO}

Na dinâmica do ordenamento do território contemporâneo, reflete-se um espaço urbano engendrado por uma ordem capitalista, e faz-se necessário a elaboração de Políticas Públicas para realizar soluções promotoras de qualidade e justiça social, as quais ordenam o território, para efetivação da organização do espaço urbano em seu desenvolvimento econômico, social, cultural e ambiental (RUMBLE et al., 2019). Desafio para o olhar geográfico.

A justificativa, aqui, é o de verificar intervenções do Estado das políticas públicas no urbano, bem como a idealização do desenvolvimento do espaço urbano. A motivação desta pesquisa foi averiguar as transformações e transições do espaço urbano que objetivaram a qualidade de vida da sociedade. Considera-se relevante colocar em pauta um tema bastante recorrente, contudo, muitas vezes discutido de modo fragmentado.

Neste contexto, Corrêa (1995, p.6) considera "a cidade como espaço urbano, sua análise geográfica é feita de diferentes modos, de acordo com as diversas correntes do pensamento Geográfico". Portanto, a cidade, em seu espaço urbano, reflete as características da sociedade, sendo assim a expressão concreta das relações sociais. Pode-se afirmar que o espaço urbano é fragmentado, articulado, reflexo e condicionante social, sendo um conjunto de usos da terra, conjunto de símbolos e campo de lutas, cada um deles como uma forma espacial, com cada uma das suas partes mantendo relações espaciais com as demais, com intensidade muito variável (CORREA, 1995).

Vemos assim, o espaço urbano reflete a própria sociedade, a qual, por meio de processos sociais contínuos, acaba por defini-lo como desigual e mutável, condicionante social, cenário e objeto das lutas sociais, materializando-se através das formas espaciais que simbolizam a história da cidade (CORREA, 1995).

Parte-se da premissa de que quando se pensa sobre políticas públicas reporta-se as ações voltadas a um território, construídas a partir de intenção de discursos de interesses e conflitos sociais. Sendo assim, pela análise espacial e do território concebe-se a relação entre geografia e políticas públicas, uma vez que essas são capazes de ordenar, reordenar e desordenar seus elementos, ou até criar novos arranjos territoriais, dependendo das intenções e finalidades. Assim, a "geografia produzida pelas políticas públicas será resultado não somente de sua imposição no espaço, mas como ela se adapta às demais geografias preexistentes" (FERNANDES, 2015, p. 77).

As reflexões apresentadas neste artigo, então, permitem complementar e ampliar o entendimento sobre geografia e políticas públicas, em especial àquelas vinculadas ao território. 


\section{INTERVENÇÕES NO TERRITÓRIO DE GUARAPUAVA A PARTIR DE CONVENIOS FEDERAIS}

A realidade urbana se constitui por vários agentes produtores do espaço, que possuem interesses distintos e divergentes, gerando conflitos denominados como territoriais por Serrano (2013). O autor aponta ainda que a "função da política urbana seria gerir tais conflitos das relações que esses agentes estabelecem entre si" (SERRANO, 2013, p.200)., visto que estão inseridos em temporalidades e espacialidades de cada formação sócio espacial capitalista.

Portanto, levando em conta essa abordagem, busca-se discutir a aprovação (escala federal) e a implementação (escala local) de políticas públicas urbanas para Guarapuava, pois a partir da Constituição de 1988 (BRASIL, 1988) houve nítidas mudanças nos discursos e investimentos no que tange às políticas públicas, até então de caráter neoliberais, para ações com maior participação do Estado, via planos governamentais desenvolvidos entre 2003 e 2016.

No entanto, mesmo com a distribuição de competências, pela descentralização e a municipalização das políticas públicas, o grande impacto político nas contabilidades eleitorais, o jogo de distribuição dessas competências, e sua relação com as condições de exercício das mesmas, também tem sido um enorme campo de disputa e de dificuldade de construção de políticas claras, estáveis e duradouras (ROLNIK, 2006). Em meio a essa constatação, é possível afirmar que a escala local se fortalece como autônoma e federativa, mas sem recursos financeiros,

Segundo seu Art. $1^{\circ}$ "A República Federativa do Brasil [é] formada pela união indissolúvel dos Estados e Municípios e do Distrito Federal..." e em seu Art. 18. "A organização política administrativa da República Federativa do Brasil compreende a União, os Estados, o Distrito Federal e os Municípios, todos autônomos, nos termos desta Constituição". Os municípios se auto organizam através de sua Lei Orgânica e por meio de eleições diretas e de leis municipais. De acordo com o Art. 29 da Constituição Federal (1988), o "município reger-se-á por lei orgânica" competindo a ele "legislar sobre assuntos de interesse local" (Art. 30 C.F). Com o processo de descentralização política os municípios brasileiros foram elevados a membros da Federação, como pode ser observado nos Artigos $1^{\circ}$ e $18^{\circ}$ da Constituição Federal de 1988 (ROLNIK, 2006, p 201).

Chega-se ao fato de que os municípios participam na formulação das Políticas Públicas e apresentam uma disposição/oferta de mais subsídios de recursos federais. Do total de grandes repasses, por meio de convênios/ parcerias entre governo federal e governo municipal, a área da educação atingiu maior volume nos últimos anos; em segundo lugar o desenvolvimento regional e em terceiro a saúde (Fig. 1). 
Figura 1: Áreas de maiores transferências do governo federal para o governo municipal de Guarapuava, PR entre 1994 a 2019.

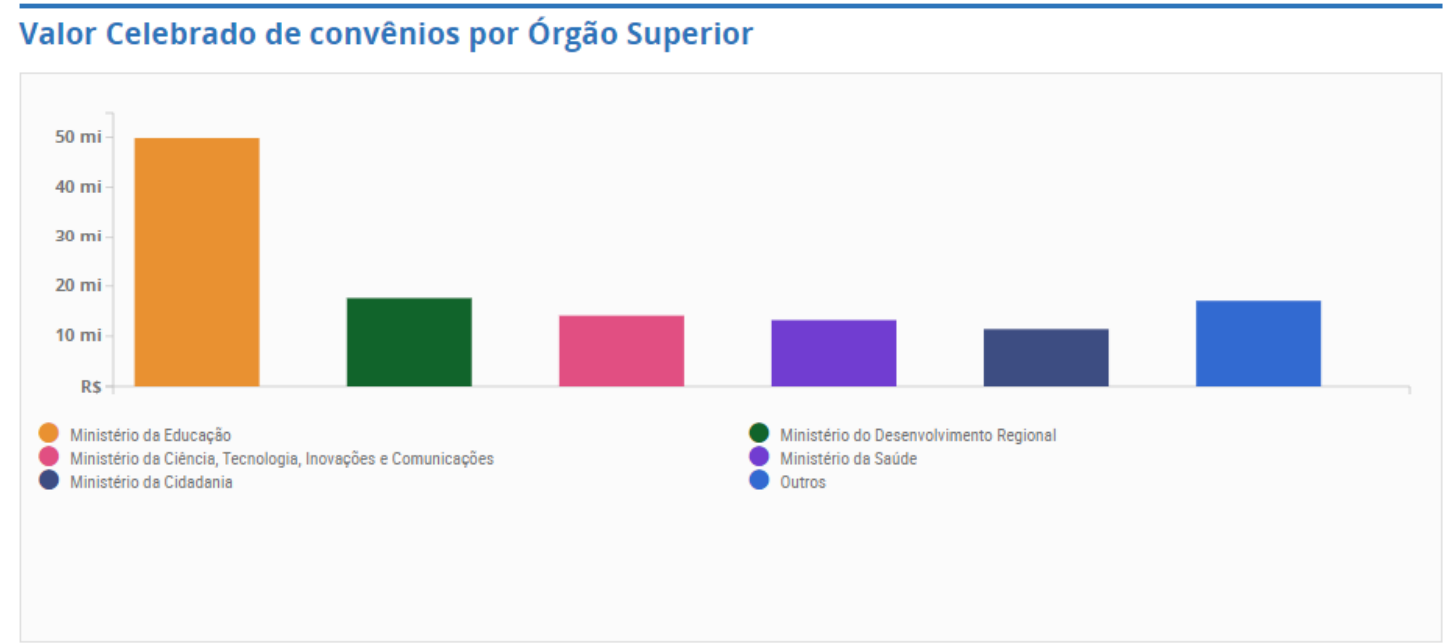

Fonte: Portal da Transparência Governo Federal (2019).

A partir da criação do Ministério das Cidades, em 2003, inicia-se mudanças nos discursos sobre a política pública urbana, o qual concretiza-se em leis e projetos o Estatuto da Cidade (BRASIL, 2001). Nesse estabelece os objetivos, diretrizes, prioridades e concomitante a criação do conselho e um fundo nacional com vistas para o financiamento desses convênios, estudados neste trabalho, e entre outros (SERRANO, 2013).

Todavia, sabemos que os municípios brasileiros são formados e substanciados por transferências de recursos e receitas federais e estaduais. E que parte dessas receitas são utilizadas para manutenção dos equipamentos urbanos e realização de obras de infraestrutura (VIANA; ARRAIS, 2012). Ressalta-se aqui, o Estado (Federal, Estadual e Municipal) como o ente regulador, desempenhando um papel fundamental no processo de produção do espaço urbano, pois dita os ritmos e os locais de crescimento, porém sempre favorecendo a classe dominante e o mercado imobiliário (TÖWS; POSTALI; MENDES, 2012). Para Correa (2011, p. 43) por a produção do espaço, seja o da rede urbana, seja intraurbano, não é o resultado da mão invisível do mercado, nem de um Estado hegeliano, visto como entidade supra orgânica, ou de um capital abstrato que emerge fora das relações sociais. Contudo, é consequência da ação de agentes sociais concretos, históricos, dotados de interesses, estratégias e práticas espaciais próprias, portadores de contradições e geradores de conflitos, entre eles mesmos e outros segmentos da sociedade. A despeito dessa discussão, o autor pontua a multiplicidade de papeis que o Estado desempenha na relação da produção do espaço urbano, afirmando que "ele constitui uma arena na qual diferentes interesses e conflitos se enfrentam, "com pesos distintos no tempo e espaço", com relações de negociação, cooptação e clientelismo, aos quais a corrupção não é estranha" (CORRÊA, 2011, p. 45-46). Decorre disso a limitação orçamentária constante aos governos locais, por não terem arrecadação suficiente para resolver seus problemas, recorrendo a captação de recursos na esfera federal. 
Os convênios são regulamentados em decorrência da Portaria Interministerial $\mathrm{N}^{\mathrm{o}}$ 127, de 29 de maio de 2008, estabelecendo as normas para execução do disposto no Decreto no 6.170, de 25 de julho de 2007, que dispõe sobre as normas relativas às transferências de recursos da União mediante convênios e contratos de repasse, e dando outras providências (BRASIL, 2007). Em seu Art. $1^{\circ}$, a portaria traz suas disposições, a regulação dos convênios, os contratos de repasse e os termos de cooperação. Celebrados pelos órgãos e entidades da Administração Pública Federal com órgãos ou entidades públicas ou privadas sem fins lucrativos para a execução de programas, projetos e atividades de interesse recíproco que envolvam a transferência de recursos financeiros oriundos do Orçamento Fiscal e da Seguridade Social da União. No que se refere ao convênio, a Portaria define como:

Acordo ou ajuste que discipline a transferência de recursos financeiros de dotações consignadas nos Orçamentos Fiscais e Seguridade Social da União e tenha como partícipe, de um lado, órgão ou entidade da administração pública federal, direta ou indireta, e, de outro lado, órgão ou entidade da administração pública estadual, do Distrito Federal ou municipal, direta ou indireta, consórcios públicos, ou ainda, entidades privadas sem fins lucrativos, visando à execução de programa de governo, envolvendo a realização de projeto, atividade, serviço, aquisição de bens ou evento de interesse recíproco, em regime de mútua cooperação (BRASIL, 2007).

Seguindo o que está posto nessa portaria, os municípios devem encaminhar suas propostas via internet, como consta em seu Art. $3^{\circ}$ : Os atos e os procedimentos relativos à formalização, execução, acompanhamento, prestação de contas e informações acerca de tomada de contas especial dos convênios, contratos de repasse e termos de parceria serão realizados no Sistema de Gestão de Convênios e Contratos de Repasse - SICONV, aberto à consulta pública, por meio do Portal dos Convênios.

Desse modo, o sistema foi criado em 2008 para administrar as transferências voluntárias de recursos da União através dos convênios firmados com estados, municípios, Distrito Federal e com as entidades privadas sem fins lucrativos. Estabelece-se como uma ferramenta para agilizar a efetivação dos contratos, a transparência do repasse do dinheiro público e a qualificação da gestão financeira. A utilização do sistema contribui para a desburocratização da máquina pública e viabiliza investimentos para a educação, saúde, infraestrutura, emprego e outros setores que atendam diretamente à população.

Nesse portal é informada toda a formalização dos convênios, sendo utilizada pela administração pública e pelos técnicos da Caixa Federal Econômica, na qualidade de principal instrumento executor. No Portal da Transparência a comunidade tem acesso às informações sobre aos repasses realizados, ou seja, configura-se como um canal no qual o cidadão pode acompanhar a execução financeira dos programas de governo, em âmbito federal. Nele estão disponíveis informações sobre os recursos públicos federais transferidos pelo Governo Federal a estados, municípios e Distrito Federal e diretamente ao cidadão, bem como dados sobre os gastos realizados pelo próprio Governo Federal em compras ou contratação de obras e serviços (BRASIL, 2016). É preciso considerar, que o portal não permite um claro entendimento do que está sendo exposto, apesar de constar os dados 
dos convênios realizados desde 1996, com a indicação de valores, locais de destinação, e informações dos serviços realizados, entre outras informações e gráficos (Fig. 2).

Figura 2 - Página do site do Portal da transparência do governo federal
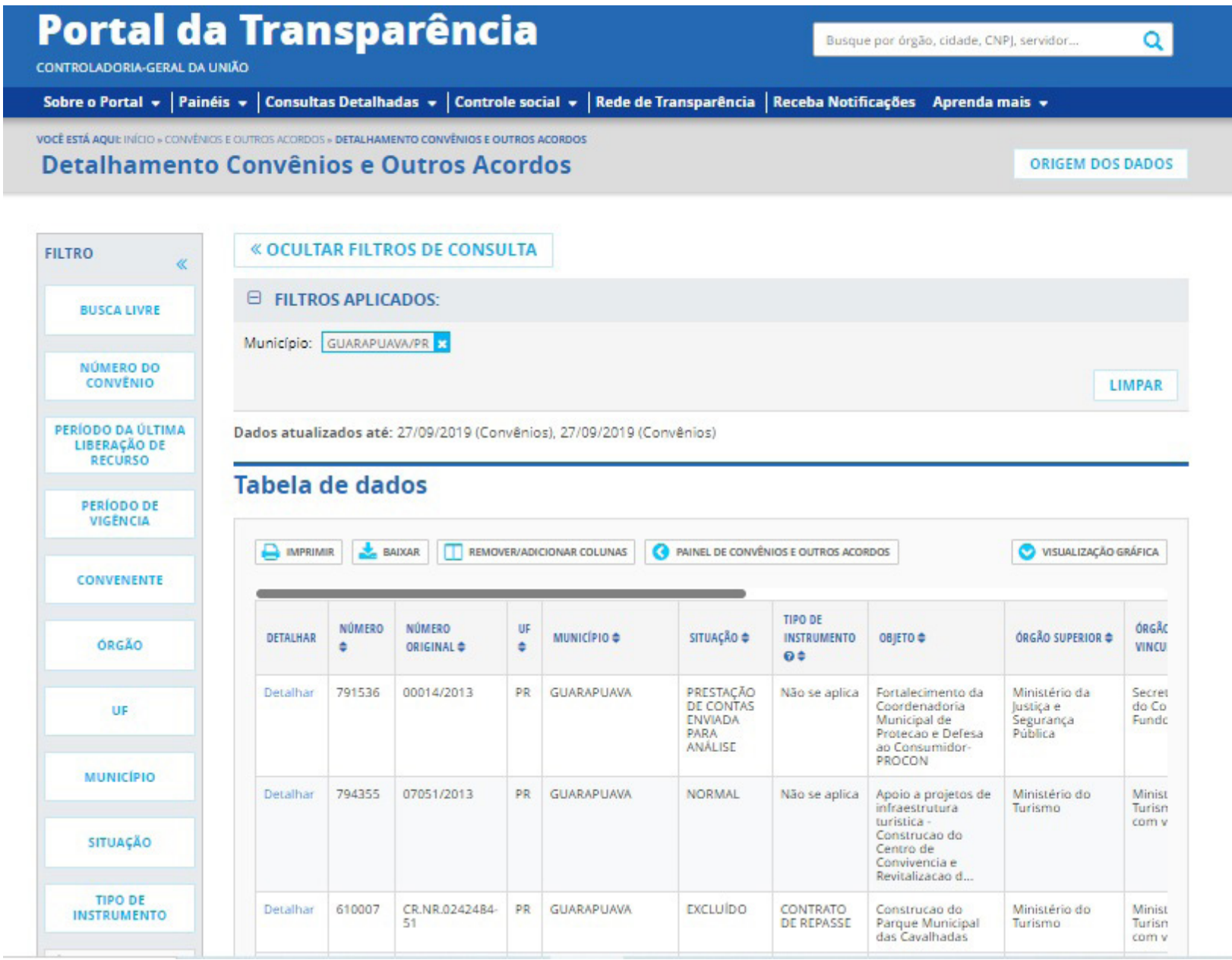

Fonte: Portal da Transparência Governo Federal (2019).

Considera-se que a disponibilidade dessas informações na internet representa um avanço na socialização da informação, muito embora parte significativa da população ainda não tenha condições de acessá-lo e a maioria dos governos municipais ainda não disponham de seus próprios portais de transparência (VIANA; ARRAIS, 2012). Os convênios realizados desde 1994 até 2019, entre o Governo Federal e os estados brasileiros estão representados na Figura 3, perfazendo um total de R \$ 479.461.556.129,41. 
Figura 3: Valor total dos recursos encerrados em convênios federais repassados aos municípios brasileiros de 1994 a 2019.

\section{Evolução histórica dos convênios - Encerrados}

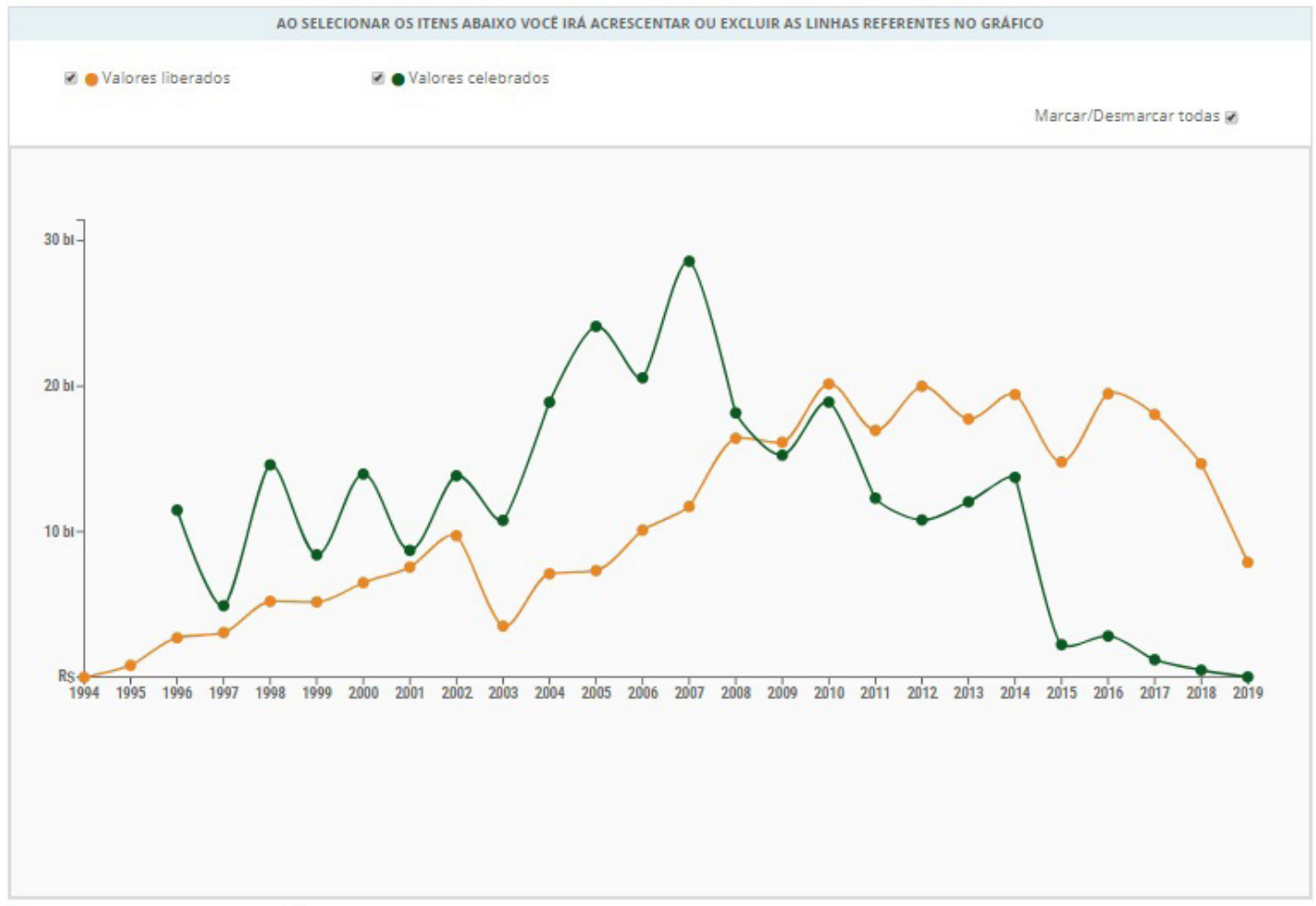

Fonte: Portal da Transparência Governo Federal (2019).

Verifica-se na Tabela 1 que o estado de São Paulo concentra o maior número de convênios celebrados entre os anos de 1994 a 2019, com um total pouco maior de 60 mil convênios, contrapondo-se com o estado do Amapá, o qual que recebeu o menor repasse, com um total de 3471 mil convênios.

Tabela 1: Detalhamento dos convênios estabelecidos entre o Governo federal e os estados brasileiros (1994 e 2019).

\begin{tabular}{lrrr}
\hline \multicolumn{1}{c}{ LOCALIDADE } & QUANTIDADE & VALOR CELEBRADO & \multicolumn{1}{c}{ VALOR LIBERADO } \\
Acre & 5.720 & $6.371 .771 .542,42$ & $4.346 .802 .864,48$ \\
Alagoas & 9.189 & $10.659 .698 .744,08$ & $7.538 .471 .316,43$ \\
Amapá & 3.471 & $3.415 .220 .988,21$ & $1.959 .383 .949,64$ \\
Amazonas & 6.782 & $7.723 .422 .031,10$ & $5.020 .108 .603,07$ \\
Bahia & 28.179 & $24.346 .504 .896,63$ & $17.129 .977 .217,45$ \\
Ceará & 23.100 & $21.691 .832 .910,39$ & $15.493 .365 .801,40$ \\
Distrito Federal & 10.292 & $108.969 .249 .429,36$ & $53.327 .643 .790,18$ \\
Espírito Santo & 10.205 & $4.653 .279 .588,32$ & $2.960 .024 .776,97$ \\
Goiás & 18.080 & $10.535 .452 .953,43$ & $7.374 .858 .601,52$ \\
Maranhão & 14.984 & $9.897 .861 .296,10$ & $6.879 .555 .593,00$ \\
& & & continua
\end{tabular}


conclusão

\begin{tabular}{|c|c|c|c|}
\hline LOCALIDADE & QUANTIDADE & VALOR CELEBRADO & VALOR LIBERADO \\
\hline Mato Grosso & 12.388 & 10.117.778.753,83 & $6.465 .964 .338,41$ \\
\hline Mato Grosso do Sul & 11.008 & 10.109.432.829,59 & 7.887.639.358,97 \\
\hline Minas Gerais & 54.640 & 28.683.676.689,37 & $19.461 .642 .802,86$ \\
\hline Pará & 13.030 & $9.633 .460 .642,02$ & $6.691 .278 .137,31$ \\
\hline Paraíba & 16.474 & $10.351 .431 .380,81$ & $7.143 .673 .892,80$ \\
\hline Paraná & 40.073 & 14.761.169.978,77 & $10.972 .891 .786,36$ \\
\hline Pernambuco & 20.564 & 24.409.632.720,19 & 17.736.077.137,16 \\
\hline Piauí & 14.060 & $8.990 .545 .290,56$ & $6.021 .435 .019,84$ \\
\hline Rio de Janeiro & 25.633 & $38.896 .424 .935,53$ & 27.304.922.268,15 \\
\hline Rio Grande do Norte & 14.891 & $8.306 .728 .304,30$ & $6.294 .258 .591,88$ \\
\hline Rio Grande do Sul & 47.833 & 19.123.977.026,36 & $14.260 .874 .106,64$ \\
\hline Rondônia & 9.198 & 4.988.686.385,86 & 3.311.195.320,99 \\
\hline Roraima & 3.735 & $6.280 .486 .663,31$ & 4.299.450.221,76 \\
\hline Santa Catarina & 25.897 & $10.974 .319 .973,73$ & 8.096.777.068,76 \\
\hline São Paulo & 60.863 & $53.294 .505 .410,66$ & $39.652 .535 .907,61$ \\
\hline Sergipe & 7.985 & $5.450 .920 .752,41$ & 3.603.209.006,52 \\
\hline Tocantins & 9.280 & $6.551 .668 .246,41$ & 4.518.552.503,27 \\
\hline Localidade não informada & 31 & $570.577,87$ & $601.332,87$ \\
\hline Exterior & 141 & $271.845 .187,79$ & $261.825 .318,88$ \\
\hline Total & 517.726 & 479.461.556.129,41 & $316.014 .996 .635,18$ \\
\hline
\end{tabular}

Fonte: Portal da Transparência Governo Federal (2019).

Org.: as autoras.

Se considerarmos a análise via distribuição de recursos pelas regiões do Brasil, durante o ano de 2016, os dados revelam que os convênios representaram maiores percentuais em relação às receitas na região Nordeste ( $38 \%$ do repasse). A região Sudeste ficou com $27 \%$, e as regiões Norte (14\%), Sul (11\%) e Centro-oeste (10\%) com o menor volume de repasses (Fig. 4). 
Figura 4: Distribuição de recursos federais através de convênios, por região, em 2016.

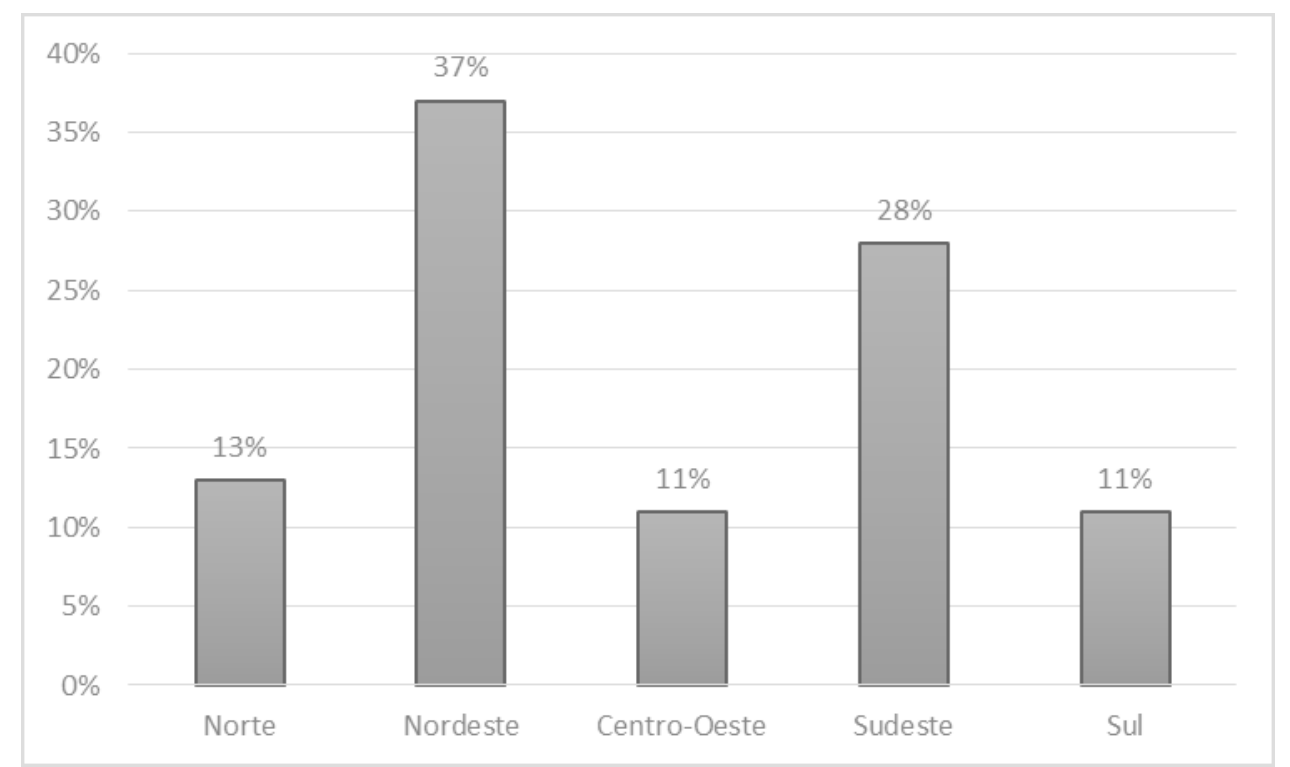

Fonte: Portal da Transparência Governo Federal (2016).

Org.: as autoras.

As discrepâncias no número de convênios estabelecidos nas regiões brasileiras demonstram que fatores demográficos e geográficos, além da formação histórica das regiões, compreendem uma complexa conjuntura de relações tanto política como sociais, que acabam refletindo na distribuição de recursos federais.

Para a região Sul, no ano de 2013 a 2016 mais de 127 bilhões foram conveniados (Fig. 5). Nesse período, o estado do Paraná teve um repasse de 39\% desse total, mesmo valor que o estado do Rio Grande do Sul, enquanto o estado de Santa Catarina recebeu repasses pouco menores, de $22 \%$.

Figura 5: Região Sul: Transferência anual de recursos de 2013 a 2016.

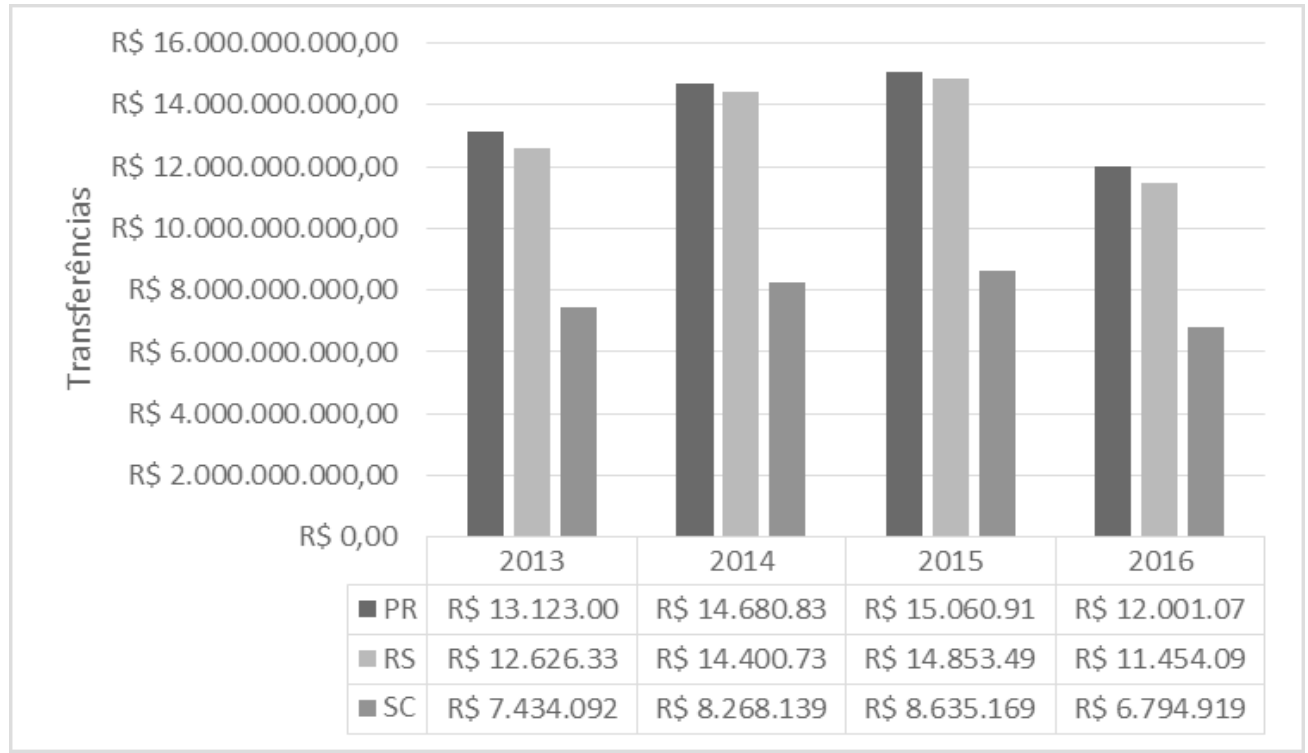

Fonte: Portal da Transparência Governo Federal (2016).

Org.: as autoras. 
Pode-se observar, pelos dados da Figura 6, que o município de Guarapuava recebeu um montante de $\mathrm{R} \$ 460.874 .220,45$ em transferências em convênios celebrados com o governo federal, entre o período de 2013 a 2016. Dessa forma, apresenta-se como o nono do estado em destinação de repasses de convênios, com mais de 292 projetos de recursos captados junto ao governo federal. As principais ações realizadas estão voltadas para saúde, assistência social, educação e urbanismo. Na categoria urbanismo, entre 1996 e 2016 há 18 convênios já executados e em fase de implantação.

Figura 6: Guarapuava: Transferência de recursos de convênios federais entre 2013 e 2016.

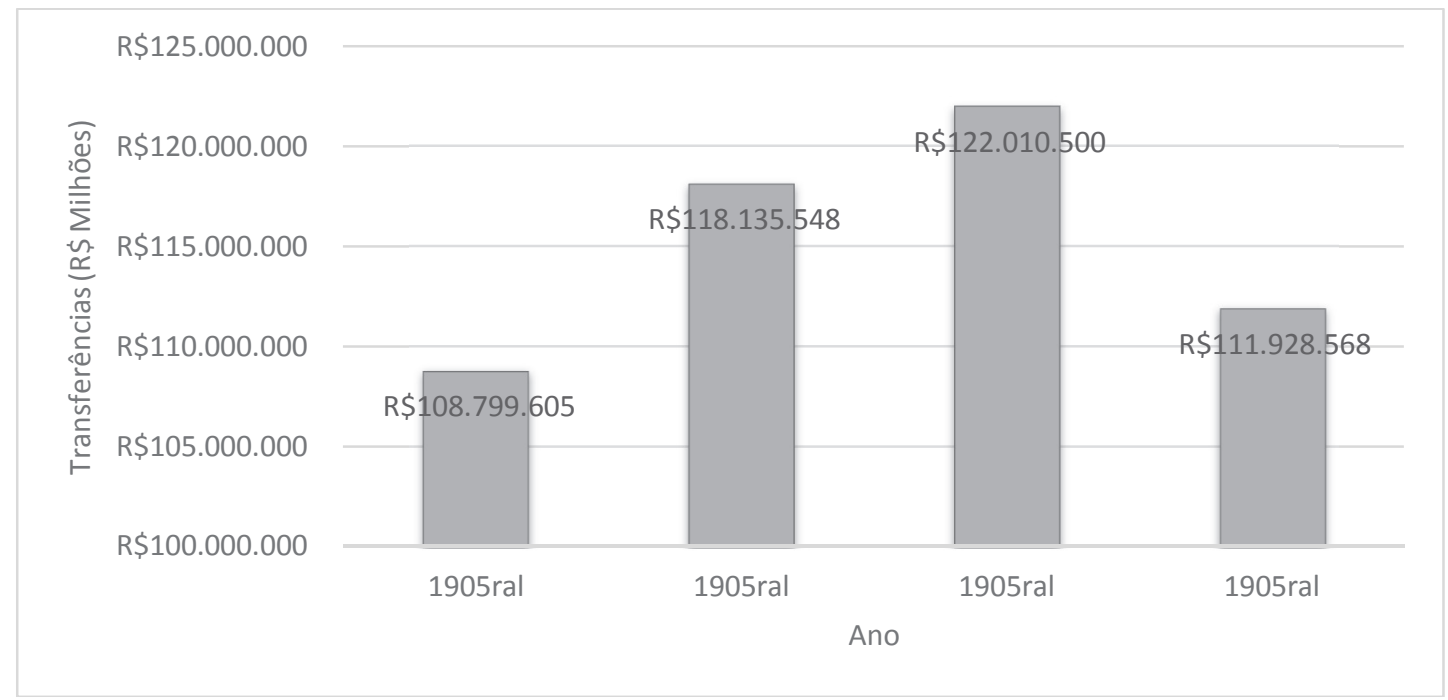

Fonte: Portal da Transparência Governo Federal (2016).

Org.: as autoras.

Rodrigues (2014, p. 34) destaca que as intervenções urbanas são realizadas "nos tecidos urbanos já existentes através de um conjunto de projetos e programas", como a reestruturação ou revitalização de atividades e/ou serviços, a recuperação ou reabilitação arquitetônica ou a reapropriação social e/ ou cultural (RODRIGUES, 2014). Para Colvero (2010) as intervenções urbanas podem ser divididas a partir de cinco princípios, de acordo com seus propósitos (Fig. 7).

Figura 7: Princípios de Intervenções urbanas

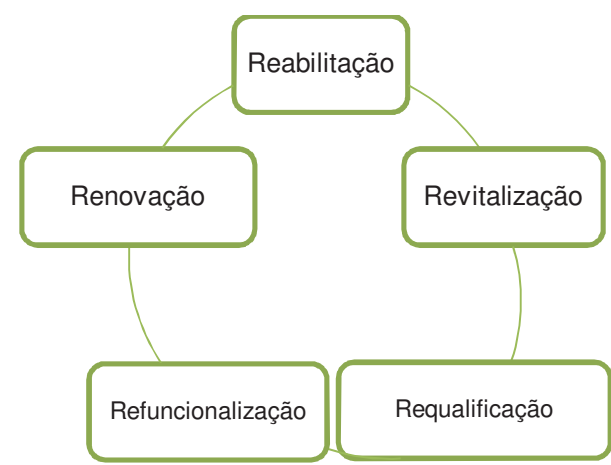

Fonte: Colvero (2010).

Org.: as autoras. 
A reabilitação caracteriza-se como política dirigida às áreas consolidadas da cidade para a valorização de potencialidades sociais e econômico-funcionais. O patrimônio edificado é incorporado como objetivo do planejamento físico-territorial, e a reabilitação das residências é tomada como a ação de manutenção física e da composição social dos seus moradores (COLVERO, 2010, p.39).

A renovação, por sua vez, apresenta-se por projetos de modernização do território, com mudanças formais e sociais, que na maioria dos casos resulta em demolição de bens construídos para que esse espaço seja renovado pela concepção do empreendedorismo urbano (COLVERO, 2010, p.39). Frequentemente esse processo resulta em exclusão social e territorial.

Ainda, segundo a mesma fonte, a revitalização visa à dinamização cultural, turística e de consumo, com investimentos em projetos de reforma e embelezamento, como exemplo, fachadas dos prédios e dos espaços públicos, com segurança pública e lazer, a fim de retomar o efeito simbólico da memória histórica do lugar, no cotidiano das pessoas que o usam e ocupam.

Colvero afirma que a requalificação engloba os conceitos anteriores, porém, está vinculada a ações que propõem qualidade socioambiental a alguns setores urbanos, sendo uma ação baseada na relação entre processos de produção social do território e sua realidade como lugar da vida e de memória. Por fim, a refuncionalização, que também é direcionada pelos conceitos anteriores, tem como objetivo reestabelecer as funções do espaço urbano.

Verifica-se esses processos se apresentando em Guarapuava, a partir das requalificações dos espaços, com parcerias público-privadas, operações urbanas, convênios, dentre outras possibilidades. Como exemplo podemos elencar um dos 35 convênios estudados na pesquisa, a Reurbanização da XV de Novembro. O poder público, portanto, ainda é um dos principais atores responsáveis pela valorização da terra urbana, uma vez que detém em suas mãos o controle e o poder sobre o território, seguindo normativas do Plano Diretor Municipal.

A esse respeito, destacamos que em 2013, Guarapuava promoveu um novo plano de governo, com a posse do prefeito eleito em 2012, filiado ao PPS - Partido Popular Socialista, do qual participa de um dos principais grupos de poder político de Guarapuava1. Ao assumir, este reestruturou a administração direta da Prefeitura Municipal, retirando da Secretaria de Habitação e Urbanismo a vinculação de realizar o cadastramento de propostas para o Governo Federal, repassando essa atividade para a Secretaria de Planejamento. Essa, por sua vez, passou a administrar todos os convênios estabelecidos com o Governo Federal e a plataforma SICONV - Sistema de Convênios. O Quadro 1 resume as falas de representantes do setor público entrevistados no segundo semestre de 2016 para esta pesquisa.

1 “Muitas vezes, e parece que este é o caso, os grupos de poder (econômico, político, simbólico) legitimam suas ideias e ações e parecem tornar-se, pelo menos por um período, quase que insubstituíveis. Isso se deve à representação que adquirem, aos valores que disseminam, às ideias que imprimem como verdades, pelo menos para parte da população. A tradução desse processo se dá em anos e anos no poder político ou em outros poderes por eles ou por suas práticas sustentados" (SILVA, 2009, p. 186). 
Quadro 1: Resumo dos principais relatos dos representantes do setor público que evidenciam o cadastramento de propostas para o Governo Federal.

Quando essa gestão assumiu, a gestão entendeu que ela precisava desmembrar a secretaria de planejamento da secretaria de finanças. Porque a secretaria de planejamento tem uma função muito importante dentro da esfera municipal, e começou a se desvincular da secretaria de finanças e se criar os departamentos, que se conduziu com as responsabilidades da secretaria. Então a secretaria de planejamento ficou desmembrada em capitação de recursos e a parte orçamentaria da prefeitura municipal. Hoje é um pouco diferente ainda, a secretaria de planejamento o departamento dela é a captação de recursos e a gestão de projetos e o orçamento voltou a ser junto com a secretaria de finanças (NASCIMENTO, 2016).

A relação ficou bem mais institucional, entre o que são verbas já carimbadas, ou seja, saúde ou educação, e em relação as obras de grande porte que já estão em programas estabelecidos por emendas parlamentares, ou seja por programas de financiamento. Veja assim é bem institucional mesmo, não tem mais aquela ajuda financeira para aquele ou aquele município, basicamente vai daquilo que o município planejou para ser executado (SILVÉRIO, 2016).

"Com o tempo e a dinâmica o governo federal foi centralizando novamente, ficamos reféns dos recursos, hoje a maioria dos municípios tem 2 a 4 \% pra investi do seu recurso, e tem que ir buscar lá no governo federal, sendo assim tem que estar muito alinhado, não politicamente, mais com a politicas federais, para pedir o recurso, pois o governo estabelece e tem que estar muito ligado com esta estrutura, dificuldades sempre existem, mais pode dizer que os desafios são grandes mais estamos enfrentando de cabeça erguida" (ALEXANDRE, 2016).

Como que funciona, tudo isso é feito através do portal de convênios SICONVE, todo mundo tem acesso através da internet ao portal de convênios, www.convenios.gov.br, então todo cidadão pode acessar o site, pode ver os editais que estão abertos e também tem condição de fazer a pesquisa do que o município tem de convênios com a esfera federal (NASCIMENTO, 2016).

Fazemos o monitoramento diário disso, verificamos que existe o edital e que o município se enquadra. Escrevemos um projeto junto com a secretária parceira, no caso deste exemplo, a secretaria de habitação e urbanismo, então nos sentamos junto com a equipe da secretaria de habitação e urbanismo e elabora um projeto, com objeto, objetivo específico, objetivo geral, metodologia, tramite normal de um TCC praticamente. Isso vai para a análise do governo federal, o município tem que dar uma contrapartida, geralmente é entre 1\% e $8 \%$ do valor total, e isso é submetido à análise do ministério. O ministério aprovando o projeto, ai simé feito o termo de parceria, com a cota de repasse, conforme for designado pelo ministério. Então, as vezes as pessoas julgam, mas infelizmente isso é engessado, e o que conseguimos captar para o município hoje, é captado, independente de área ou setor. É possível, vamos atrás de recurso para melhorar a infraestrutura da cidade, para fazer a cidade crescer (NASCIMENTO, 2016).

Fonte: Entrevistas, 2016.

Org.: as autoras.

Observa-se, por meio dos relatos dos entrevistados, que através dessa estrutura modificada o governo local conseguiu viabilizar convênios em várias áreas, apresentando novos projetos para o governo federal, por meio dos editais publicados em Diário Oficial da União (Quadro 2). 
Quadro 2 - Contratos de repasse de recursos federais para transferências para a área urbana de Guarapuava, PR entre 2013 e 2016.

\begin{tabular}{|c|c|c|c|c|c|}
\hline CONV. & OBJETO & SITUAÇÃO & EXEC. & VÍNCULO & $\begin{array}{l}\text { CONTRAPARTIDA } \\
\text { (R\$) }\end{array}$ \\
\hline $\begin{array}{l}790371 / \\
2013\end{array}$ & $\begin{array}{l}\text { Construção de abrigos de ônibus para } \\
\text { embarque e desembarque de passageiros } \\
\text { usuários do transporte público no município. }\end{array}$ & $\begin{array}{l}\text { Empenhado, } \\
\text { publicado e } \\
\text { assinado }\end{array}$ & $\begin{array}{l}23 / 12 / 13 \\
\mathrm{a} \\
30 / 11 / 17\end{array}$ & $\begin{array}{l}\text { Ministério } \\
\text { das Cidades }\end{array}$ & $42.879,00$ \\
\hline $\begin{array}{l}794852 / \\
2013\end{array}$ & $\begin{array}{l}\text { Regularização Fundiária em áreas Urbanas } \\
\text { (Papel Passado) }\end{array}$ & $\begin{array}{l}\text { Empenhado, } \\
\text { publicado e } \\
\text { assinado }\end{array}$ & $\begin{array}{l}23 / 12 / 13 \\
\mathrm{a} \\
30 / 12 / 17\end{array}$ & $\begin{array}{l}\text { Ministério } \\
\text { das } \\
\text { Cidades* }\end{array}$ & $10.916,70$ \\
\hline $\begin{array}{l}794355 / \\
2013\end{array}$ & $\begin{array}{l}\text { Apoio a projetos de infraestrutura turística } \\
\text { - Construção do Centro de Convivência e } \\
\text { Revitalização do Parque de Recreação, Esporte } \\
\text { e Lazer do Jordão }\end{array}$ & $\begin{array}{l}\text { Empenhado, } \\
\text { publicado e } \\
\text { assinado }\end{array}$ & $\begin{array}{l}30 / 12 / 13 \\
\mathrm{a} \\
30 / 03 / 17\end{array}$ & $\begin{array}{l}\text { Ministério } \\
\text { do Turismo }\end{array}$ & $78.000,00$ \\
\hline $\begin{array}{l}789601 / \\
2013\end{array}$ & $\begin{array}{l}\text { Reurbanização da rua XV de novembro através } \\
\text { de pavimentação asfáltica com canteiro central, } \\
\text { rótulas, meio fio com sarjetas, sinalização } \\
\text { viária, drenagem com galeria de águas } \\
\text { pluviais, implantação de passeios públicos } \\
\text { com acessibilidade. }\end{array}$ & $\begin{array}{l}\text { Empenhado, } \\
\text { publicado e } \\
\text { assinado }\end{array}$ & $\begin{array}{l}31 / 12 / 13 \\
\mathrm{a} \\
30 / 05 / 17\end{array}$ & $\begin{array}{l}\text { Ministério } \\
\text { das } \\
\text { Cidades* }\end{array}$ & $1.538 .847,85$ \\
\hline $\begin{array}{l}809668 / \\
2014\end{array}$ & $\begin{array}{l}\text { Pavimentação, drenagem pluvial, ampliação } \\
\text { na largura das pistas pavimentadas, } \\
\text { recapeamento asfáltico, sinalização viária } \\
\text { e implantação de passeios públicos com } \\
\text { acessibilidade no distrito da palmeirinha em } \\
\text { Guarapuava-PR. }\end{array}$ & $\begin{array}{l}\text { Empenhado, } \\
\text { publicado e } \\
\text { assinado }\end{array}$ & $\begin{array}{l}14 / 07 / 14 \\
\mathrm{a} \\
30 / 07 / 17\end{array}$ & $\begin{array}{l}\text { Ministério } \\
\text { das Cidades }\end{array}$ & $171.878,26$ \\
\hline $\begin{array}{l}806496 \\
/ 2014\end{array}$ & $\begin{array}{l}\text { Implantação e Modernização de Infraestrutura } \\
\text { para Esporte Educacional, Recreativo e de } \\
\text { Lazer - Revitalização do Espaço de Esporte e } \\
\text { Lazer do Trianon. }\end{array}$ & $\begin{array}{l}\text { Empenhado, } \\
\text { publicado e } \\
\text { assinado }\end{array}$ & $\begin{array}{l}30 / 07 / 14 \\
\mathrm{a} \\
30 / 07 / 17\end{array}$ & $\begin{array}{l}\text { Ministério } \\
\text { do Esporte }\end{array}$ & $38.152,17$ \\
\hline $\begin{array}{l}815155 / \\
2014\end{array}$ & $\begin{array}{l}\text { Reforma do Terminal Rodoviário Municipal de } \\
\text { Guarapuava } 1^{\text {a }} \text { Etapa, localizado na Avenida } \\
\text { Sebastião de Camargo Ribas, } n^{\circ} 2.301 \text {, Bairro } \\
\text { Bonsucesso. - Emendas Parlamentares }\end{array}$ & $\begin{array}{l}\text { Empenhado, } \\
\text { publicado e } \\
\text { assinado }\end{array}$ & $\begin{array}{l}30 / 12 / 14 \\
\mathrm{a} \\
30 / 08 / 17\end{array}$ & $\begin{array}{l}\text { Ministério } \\
\text { do Turismo }\end{array}$ & $94.856,21$ \\
\hline $\begin{array}{l}819889 / \\
2015\end{array}$ & $\begin{array}{l}\text { Construção de abrigos de ônibus para usuários } \\
\text { do Transporte Público no Município de } \\
\text { Guarapuava-PR }\end{array}$ & $\begin{array}{l}\text { Empenhado, } \\
\text { publicado e } \\
\text { assinado }\end{array}$ & $\begin{array}{l}04 / 11 / 15 \\
\mathrm{a} \\
30 / 09 / 18\end{array}$ & $\begin{array}{l}\text { Ministério } \\
\text { das Cidades }\end{array}$ & $9.862,00$ \\
\hline $\begin{array}{l}819896 / \\
2015\end{array}$ & $\begin{array}{l}\text { Obras integradas de reabilitação e de } \\
\text { acessibilidade urbana na Cidade de } \\
\text { Guarapuava-PR. }\end{array}$ & $\begin{array}{l}\text { Empenhado, } \\
\text { publicado e } \\
\text { assinado }\end{array}$ & $\begin{array}{l}14 / 12 / 15 \\
\mathrm{a} \\
30 / 12 / 18\end{array}$ & $\begin{array}{l}\text { Ministério } \\
\text { das Cidades }\end{array}$ & $194.455,69$ \\
\hline $\begin{array}{l}831538 / \\
2016\end{array}$ & $\begin{array}{l}\text { Esporte e Grandes Eventos Esportivos - } \\
\text { Implantação e Modernização de Infraestrutura. }\end{array}$ & $\begin{array}{l}\text { Empenhado, } \\
\text { publicado e } \\
\text { assinado }\end{array}$ & $\begin{array}{l}25 / 05 / 16 \\
\mathrm{a} \\
30 / 05 / 18\end{array}$ & $\begin{array}{l}\text { Ministério } \\
\text { do Esporte }\end{array}$ & $4.680,00$ \\
\hline $829725 / 2016$ & $\begin{array}{l}\text { Obras de pavimentação asfáltica em CBUQ, } \\
\text { galeria de águas pluviais, calçadas, sinalização } \\
\text { viária e acessibilidade e mobilidade da rua } \\
\text { Saldanha Marinho }\end{array}$ & $\begin{array}{l}\text { Empenhado, } \\
\text { publicado e } \\
\text { assinado }\end{array}$ & $\begin{array}{l}31 / 08 / 16 \\
\mathrm{a} \\
30 / 10 / 19\end{array}$ & $\begin{array}{l}\text { Ministério } \\
\text { das Cidades }\end{array}$ & $30.000,00$ \\
\hline $834834 / 2016$ & $\begin{array}{l}\text { Pavimentação asfáltica em CBUQ, galeria } \\
\text { de águas pluviais, calçadas, sinalização } \\
\text { viária e mobilidade urbana no Município de } \\
\text { Guarapuava-PR. }\end{array}$ & $\begin{array}{l}\text { Empenhado, } \\
\text { publicado e } \\
\text { assinado }\end{array}$ & $\begin{array}{l}31 / 08 / 16 \\
\mathrm{a} \\
30 / 08 / 19\end{array}$ & $\begin{array}{l}\text { Ministério } \\
\text { das Cidades }\end{array}$ & $3.000,00$ \\
\hline
\end{tabular}

Fonte: as autoras. 
Dos 35 convênios efetivados entre o governo federal e o governo local, foram celebrados 12 convênios destinados a área urbana. O Ministério das Cidades é responsável pelo maior volume de repasses para a área urbana de Guarapuava, especialmente via planejamento e implementação de obras urbanas, programas de habitação, transportes urbanos e saneamento básico, totalizando aí oito convênios.

Considerando os convênios desenvolvidos pela esfera federal, de maneiras distintas, apresenta-se um desafio repensar o ordenamento de cidades mais equilibradas, eficientes e justas, com o objetivo de implementar políticas públicas urbanas que, "além de mobilizar recursos financeiros, introduzam mecanismos permanentes de acesso à terra legal e formal por parte dos mais pobres, redesenhando a natureza e instrumentos até agora em vigor no campo do planejamento e gestão do solo urbano em nossas cidades" (ROLNIK, 2006, p.201). Pois esse contexto enseja uma perspectiva de "auto segregação", como evidência Töws (2015, p. 150):

Compreende a um aspecto do processo corrosivo de determinados valores e relações sociais. As classes médias e altas continuarão se enclausurando atrás de muros e cercas eletrificadas, enquanto não se puser em um movimento consistente de mudança sócio espacial que faça tais medidas aparecerem como desnecessárias.

Mediante uma pequena síntese desses dados analisados, conduz-se por conflitos de interesses, que por vezes ditam as regras dos convênios e parcerias em esfera federal/local, condicionadas por padrões de urbanização, delineando os investimentos de transformação urbana. Atribui-se, então, uma lógica de concorrência, de busca de investimentos para a acumulação do capital que transforma o espaço urbano economicamente, em sua morfologia e infraestrutura.

Oliveira e Flores (2016, p.226) tem como proposta abordar o "projeto urbano", a partir da ocupação por "dimensão formal, estética e funcional da cidade de acordo com sua ambição estratégica", considerando que "pequenas intervenções resultam na execução de um projeto maior de cidade", conduzindo a projetos urbanos com "a finalidade de desenvolver um pedaço da cidade por renovação, intensificação ou criação do zero".

Portanto, Guarapuava insere-se na concepção de projeto urbano, adequando-se as cinco propostas de Oliveira e Flores (2016) citadas abaixo.

a) A aplicação de um procedimento, levando em consideração os mecanismos de gestão e articulação público-privada;

b) Um arranjo político, além de uma configuração no espaço e no tempo;

c) A consideração da escala dos impactos sócio espaciais para que ultrapassem seu entorno imediato;

d) Algo que ressalta a complexidade, não só em razão da articulação de múltiplos atores, mas também da complexidade de usos; e) Uma operação concertada entre múltiplos atores e com diversos impactos no espaço urbano e no desenvolvimento econômico e social da cidade. 
Perante esse processo, cabe retornar aos primeiros itens aqui apontados, e pensar como esses convênios são desenvolvidos através das diretrizes e princípios norteadores de ação do poder público, que criam regras e procedimentos para as relações entre poder público e sociedade, e por vezes mediam as relações entre atores da sociedade e do Estado (TEIXEIRA, 2002, p.2).

Para além dos recursos locais de arrecadação de impostos, cabe afirmar que há um conjunto de fatores que tornaram o município, ao longo dos anos, um "cliente preferencial, um espaço econômico privilegiado de acumulação" (CUSTÓDIO, 2005, p. 102). Com isso, seria comum chegar-se ao ponto da "complexidade do que seja ordenar, planejar e gerenciar o território municipal no momento" (CUSTÓDIO, 2005, p. 102), sendo essencial ressaltar a dimensão do papel dos poderes e a grande necessidade da elaboração de políticas públicas.

Sem dúvida, a intermediação dos interesses dos diversos segmentos da sociedade está conjugada na formulação de políticas públicas. Por conseguinte, produzir algo através da ordenação de seus elementos constituintes e pela participação efetiva da sociedade, pela transparência e publicidade dos dados e atos da administração pública, que "podem favorecer a ruptura com uma tradição encontrada em grande parte dos municípios brasileiros, que são políticas de cunho paternalista, populista e clientelista" (FONSECA, 2009, p. 62).

Para Teixeira (2002), nesse caso, são produzidas as políticas explicitadas, sistematizadas ou formuladas em documentos (leis, programas, linhas de financiamento) que orientam ações que normalmente envolvem aplicações de recursos públicos. Esses convênios (considerados na pesquisa como as políticas públicas urbanas) traduzem, tanto no seu processo de elaboração como de implementação, formas de exercício do poder político, que envolve a distribuição e a redistribuição de dominação e de apropriação, refletidas no conflito social nos processos de decisão, com a repartição de custos e benefícios sociais (TEIXEIRA, 2002, p. 2).

O Estatuto da Cidade adota, como diretrizes gerais da política urbana, nos termos do artigo $2^{\circ}$, inciso VI, a ordenação do solo urbano de forma a evitar a utilização inadequada dos imóveis urbanos, prevendo no inciso XIV a regularização fundiária e urbanização de áreas ocupadas por população de baixa renda, mediante o estabelecimento de normas especiais de urbanização, uso e ocupação do solo e edificação, consideradas a situação socioeconômica da população e as normas ambientais. A abordagem acontece via intervenção urbana, a qual tem como objetivo principal recuperar ou reabilitar uma estrutura ou parte do espaço urbano. Conclui-se que os conceitos aqui revisados estão associados e se estabelecem no espaço urbano da cidade média de Guarapuava, com a implementação de políticas públicas para reordenar e ajustar problemas urbanos, mas não problemas socioeconômicos urbanos.

\section{CONSIDERAÇÕES FINAIS}

A finalidade deste artigo foi em discorrer sobre reflexões que possam subsidiar as posteriores discussões a respeito das recentes políticas públicas empreendidas para a 
realidade urbana de Guarapuava, e as transformações ocorridas neste território, como o processo de implementação dos programas urbanos nacionais, analisando a importância das políticas públicas. As reflexões apresentadas neste artigo, por ora uma análise superficial em algumas situações, permitem complementar e ampliar o entendimento sobre geografia e políticas públicas, em especial àquelas vinculadas ao território.

Todavia, é preciso avançar muito mais e em escalas coletivas, porque as políticas não avançam sozinhas, e estão inseridas no território de maneira setorial, isolada e fragmentada. No que se refere a uma pequena síntese desses dados analisados, somos conduzidos por conflitos de interesses, que por vezes ditam as regras dos convênios em esfera local e federal. Para tanto, pontuamos brevemente outro aspecto importante de se mencionar, é o fato de estudarmos uma cidade média, cujas dinâmicas políticas são direcionadas por grupos de poder estabelecidos.

Diante disso, para a efetivação das políticas públicas urbanas, num viés integrado, no contexto do ordenamento do território, é necessário que os problemas urbanos, antes de entrarem na agenda federal, sejam analisados, discutidos, planejados e que seja considerado a realidade na qual será implementada as políticas públicas, visando transformação.

\section{REFERÊNCIAS}

ALEXANDRE, F. Prefeitura de Guarapuava. Entrevista concedida em 22 jun. 2016.

BRASIL. Constituição da República Federativa do Brasil. Diário Oficial [da] República Federativa do Brasil, Brasília, 05 out. 1988. Disponível em: https://www.planalto.gov.br/ccivil_03/Constituicao/ DOUconstituicao88.pdf Acesso em: 02 dez. 2016.

BRASIL. Lei $n^{\circ}$ 10.257, de 10 de julho de 2001. Regulamenta os arts. 182 e 183 da Constituição Federal, estabelece diretrizes gerais da Política urbana e dá outras providências. Diário Oficial [da] República Federativa do Brasil, Brasília, 10 jun. 2001. Disponível em: http://www2.camara.leg.br/legin/fed/ lei/2001/lei-10257-10-julho-2001-327901-normaatualizada-pl.html Acesso em: 23 jul. 2016.

BRASIL. Decreto $n^{0}$ 6.170, de 25 de julho de 2007. Dispõe sobre as normas relativas às transferências de recursos da União mediante convênios e contratos de repasse, e dá outras providências. Diário Oficial [da] República Federativa do Brasil, Brasília, 26 jul. 2007. Disponível em: http://pesquisa.in.gov.br/ imprensa/ jsp/visualiza/index.jsp?jornal=1\&página=1\&data=26/07/2007 Acesso em: 23 jul. 2016.

BRASIL. Portal da Transparência Governo federal. Disponível em: http://transparencia.gov.br/. Acesso em: 27 dez. 2016.

COLVERO, A.A. A requalificação do centro antigo da cidade de São Paulo: Políticas urbanas, planejamento participativo e gestão, no período de 2001-2004. Campinas, 2010. Tese (Doutorado em Geografia) Universidade de Campinas, UNICAMP.

CORRÊA, R.L. O Espaço Urbano. 3.ed. São Paulo: Ática, 1995.

CORREAA, R.L. Sobre agentes sociais, escala e produção do espaço: um texto para discussão. In: CARLOS, A.F.A.; SOUZA, M.L.; SPOSITO, M.E.B. A produção do espaço urbano: agentes e processos, escalas e desafios. Contexto: São Paulo, 2011. p. 41-51.

CUSTÓDIO, V. A retomada do planejamento federal e as políticas públicas no ordenamento do território municipal: a temática das águas e do saneamento. Revista do Departamento de Geografia, n. 16, p. 95 -104, 2005.

FERNANDES, S.W.R. Contribuições da ciência geográfica às políticas públicas. Brasília, 2015. Tese (Doutorado em Geografia) - Universidade de Brasília, UnB. 
FONSECA, J.F.R. O Orçamento Participativo e a Gestão Democrática de Goiânia. Goiânia, 2009. Dissertação (Mestrado em Desenvolvimento e Planejamento Territorial) - Universidade Católica de Goiás, PUC-Go.

GUARAPUAVA. Lei Complementar n 70 , de 21 de dezembro de 2016. Aprovado e instituído o plano diretor do município de Guarapuava para o decênio 2016 a 2026. Guarapuava, 2016.

GUARAPUAVA. Plano local de habitação de interesse social - PLHIS. Guarapuava, 2011.

IBGE - Instituto Brasileiro de Geografia e Estatística. Censo Demográfico 2010. Rio de Janeiro. 2010.

IBGE - Instituto Brasileiro de Geografia e Estatística. Banco de dados. Disponível em: http://www.ibge. gov.br/html. Acesso em: 20 abr. 2016.

OLIVEIRA, C.M. de; FLORES, R.K. Conflitos no espaço urbano: um Cais Mauá de Todos. Revista Brasileira de Estudos Urbanos e Regionais, v. 18, n. 2, p.224-239, 2016.

RODRIGUES, J.N. Políticas públicas e geografia: retomada de um debate. GEOUSP - Espaço e Tempo, v. 18, n. 1, p. 152-164, 2014.

NASCIMENTO, L.F.R. Prefeitura de Guarapuava. Entrevista concedida em 03 nov. 2016.

ROLNIK, R. A construção de uma política fundiária e de planejamento urbano para o país - Avanços e desafios. Boletim de Políticas Sociais. Brasília: IPEA, 2006.

RUMBLE, H.; ANGEOLETTO, F.; CONNOP, Stuart et al. Understanding and applying ecological principles in cities. In: LEMES DE OLIVEIRA, F.; MELL, I. (Eds.). Planning Cities with Nature: Theories, Strategies and Methods. Amsterdam: Springer Nature, 2009.

SERRANO, A.F. Avanços nos discursos de políticas urbanas nacionais. In: STEINBERGER, M. Território, Estado e políticas públicas espaciais. Brasília: Ler, 2013. p. 21-28.

SILVA, M. da. Saberes geográficos: teorias e aplicações. Guarapuava: Ed. Unicentro, 2009. p. 203-220.

SILVÉRIO. J.E. Prefeitura de Guarapuava. Entrevista concedida em 03 nov. 2016.

TEIXEIRA, E.C. O papel das políticas públicas no desenvolvimento local e na transformação da realidade. Santarém: FIT/UNAMA, 2002. Disponível em: http://www.dhnet.org.br/dados/cursos/ aatr2/a_pdf/03_aatr_pp_papel.pdf. Acesso em: 22 set. 2019.

TÖWS, R.L. Grandes projetos urbanos como reprodução da lógica do capital em Maringá (PR). Maringá, 2015. Tese (Doutorado em Geografia) - Universidade Estadual de Maringá, UEM.

TÖWS, R.L.; POSTALI, V.B.; MENDES, C.M. Relações de poder e produção do espaço no norte do Paraná (Brasil). In: COLÓQUIO INTERNACIONAL DE GEOCRITICA. 12, 2012, Bogotá. Anais... Disponível em: http:// www.ub.edu/geocrit/coloquio2012/actas/04-R-Tows.pdf Acesso em: 22 set. 2019.

VIANA, J.L.R.; ARRAIS, T.A. Integração espacial e gestão de recursos em ambientes metropolitanos: análise e espacialização dos convênios com o Ministério das Cidades na Região Metropolitana de Goiânia.

Geo UERJ, Rio de Janeiro, v. 1, n. 23, p. 244-261, 2012.

Data de submissão: 26/ jun./ 2017

Daa de aceite: 22/ jul./ 2019 